\title{
Therapeutic drug monitoring of benznidazole and nifurtimox: a systematic review and quality assessment of published clinical practice guidelines
}

\author{
Mario Javier Olivera ${ }^{[1]}$ Johana Alexandra Fory ${ }^{[2]}$ and Antonio José Olivera ${ }^{[3]}$
}

[1]. Grupo Parasitología, Instituto Nacional de Salud, Bogotá, Colombia.

[2]. Facultad de Medicina, Universidad Militar Nueva Granada, Bogotá, Colombia.

[3]. Facultad de Odontología, Universidad el Bosque, Bogotá, Colombia.

\begin{abstract}
The pharmacological management of adults with chronic-phase Chagas disease is challenging despite it being the recent focus of extensive research. One of the challenges in the current clinical practice guidelines (CPGs) landscape is the existence of nonevidence-based recommendations for the use of laboratory tests in treatment monitoring. This study aimed to systematically assess the quality and consistency of recommendations of CPGs on the pharmacological management of adults with chronicphase Chagas disease. Systematic literature searches were conducted in MEDLINE, EMBASE, SciELO and Google to identify all published CPGs relevant to the pharmacological management of Chagas disease, between January 2010 and March 2016. Three independent reviewers assessed the quality of each CPG using the Appraisal of Guidelines Research and Evaluation (AGREE) II instrument. A total of five CPGs were included and the overall quality of the guidelines for therapeutic drug monitoring of Chagas disease was moderate-to-low. There was considerable variation in the quality of the CPGs across the AGREE II domains. The domains of scope/purpose, stakeholder involvement, and clarity of presentation were rated well, and the domains of applicability and editorial independence received poor ratings. This review showed that the methodological quality of CPGs for Chagas disease was generally inappropriate, and there was no explicit link between the best available evidence and current recommendations.
\end{abstract}

Keywords: Chagas disease. Trypanosoma cruzi. Clinical practice guidelines. AGREE.

\section{INTRODUCTION}

Chagas disease is a zoonotic parasitic disease caused by the protozoan Trypanosoma cruzi ${ }^{1}$. Approximately 6-7 million people worldwide are estimated to be infected with T. cruzi, the majority of which are found in Latin America². Despite extensive efforts to control the disease implemented since several decades, Chagas disease remains one of the biggest public health problems in Latin America. Currently, antiparasitic treatment options for Chagas disease are limited by only two old anti-parasitic drugs, benznidazole (BZN) and nifurtimox (NFX) $)^{3,4}$.

Trypanosoma cruzi infection is curable if treatment is initiated soon after infection. Both BZN and NFX are active in the acute phase. In contrast, treatment for the indeterminate or symptomatic chronic stages of Chagas disease have been debated for many years ${ }^{5,6}$. Recent research has shown that treatment with BZN

Corresponding author: Dr. Mario Javier Olivera.

e-mail: mjoliverar@unal.edu.co

Received 3 July 2017

Accepted 30 November 2017 in patients with Chagas cardiomyopathy significantly reduced serum parasite detection, but did not significantly reduce clinically relevant cardiac deterioration? ${ }^{7}$. This reduction in parasite load is heavily dependent on geographic site, and parasite strain. Due to the above evidence, the current trend is to treat cases of Chagas disease without heart complications ${ }^{8}$.

The major disadvantage of both drugs is their toxicity profiles $^{9-12}$. Due to the high incidence of adverse drug reactions, patients require clinical monitoring and laboratory tests in order to promptly identify severe adverse effects ${ }^{13,14}$. Currently, there is no consensus on the recommendations for pharmacological management for Chagas disease with emphasis on follow-up (i.e. which clinical monitoring and laboratory tests that need to be performed).

There are several clinical practice guidelines (CPGs) for the pharmacological management of Chagas disease. However, they differ in terms of their recommendations of treatment regimens, duration thereof, and frequency of monitoring. The aim of this review was to systematically assess the quality and consistency of recommendations of CPGs on the pharmacological management of adults chronically infected with $T$. cruzi in South America. 


\section{METHODS}

\section{Search strategy and identification of clinical practice guidelines}

Systematic literature searches were conducted to identify all published CPGs relevant to the pharmacological management of Chagas disease. Databases were searched using Medical Subject Headings and key words related to Chagas disease and treatment guidelines. Searches were restricted to articles published between January 2010 and March 2016. All searches were conducted in MEDLINE, EMBASE and SciELO. The electronic database search was supplemented by searching through Google, and other secondary websites. A secondary search was carried out by consulting the bibliographic references of the included CPGs. The search strategy used was: "Chagas disease OR Trypanosoma cruzi AND Chagas/therapy AND practice guideline AND humans". A Google search was performed by country using the words "Chagas disease" and "guideline" and the first 100 items were reviewed.

\section{Selection of guidelines}

Two reviewers independently screened the search results for inclusion using a pre-defined relevance criteria form. $\mathrm{CPGs}$ were defined as recommendations intended to facilitate decision-making in health professionals and patients for the prevention and treatment of Chagas disease. To be included, a CPG had to address the following issues: I) provide practical clinical recommendations on pharmacological management for Chagas disease (adults in chronic phase) II) be endorsed by a medical specialty associations, relevant professional societies or governmental agencies of a country of South America

The CPGs of concern in this study focused exclusively on Chagas disease among special groups (e.g. those who were, pregnant or who had children). Technical standards and protocols were not considered to be CPGs.

The full-text article was obtained for potentially relevant CPGs and these were subsequently screened by two reviewers. Discrepancies at any stage were resolved by discussion, or the involvement of a third reviewer. To ensure that the most upto-date CPGs were included, inclusion was limited to articles published from January 2010. Furthermore, only CPGs written in English, Spanish or Portuguese were included.

\section{Data extraction and quality assessment}

A draft data extraction form was developed and piloted. Two reviewers independently extracted all of the data using the standardized data extraction form. Discrepancies were resolved by discussion, or through the involvement of a third reviewer. The extracted data included CPG characteristics (e.g., year of dissemination, country, development team) and recommendations related to the indications for treatment, dosage, duration of treatment, treatment monitoring, and laboratory testing (complete blood count, liver and renal function tests, and urinalysis). For each item, we noted whether the CPG recommended it, the level of evidence thereof, and the quality of the studies supporting or refuting the recommendation.
The methodological quality of existing CPGs for Chagas disease was evaluated using the Appraisal of Guidelines Research and Evaluation (AGREE) II tool by three reviewers independently ${ }^{15}$. Discrepancies were resolved by discussion. The AGREE II instrument, which consists of 23 items, grouped into six quality domains: 1) Scope and purpose (items 1-3); 2) Stakeholder involvement (items 4-6); 3) Rigour of development (items 7-14); 4) Clarity of presentation (items 15-17); 5) Applicability (items 18-21) and 6) Editorial independence (items 22-23). Each item was scored on a scale of $1-7$, with 1 being strongly disagree, and 7 being strongly agree.

\section{Statistical analysis}

A descriptive statistical analysis was used to summarize the data. The standard score for each domain was calculated as per the AGREE II instructions included in the user's manual ${ }^{15}$. The following formula was used: The scaled domain score $=$ [score obtained-minimum possible score]/[maximum possible score - minimum possible score $\mathrm{x} 100$ ], giving a percentage score between 0 and 100. The overall assessment of all the included CPGs was based on the overall quality of each guideline. The mean difference was also calculated for the scores between CPGs with their corresponding 95\% confidence intervals. An intraclass correlation coefficient (ICC) was used to measure inter-rater agreement for each guideline's scores. All statistical analyses were calculated using Statistical Package for the Social Sciences (SPSS) v.17.0 (IBM Corp., Armonk, NY, USA).

\section{RESULTS}

\section{Study selection}

The search strategy retrieved 39 records, and after application of the inclusion and exclusion criteria, 10 full-text papers were assessed and five CPGs were included in the review (Figure 1).

\section{Clinical practice guideline characteristics}

Among the five selected CPGs, one was from Colombia ${ }^{16}$ (COL), and one from each of the following countries: Argentina ${ }^{17}$ (ARG), Chile ${ }^{18}$ (CHI), Brazil ${ }^{19}$ (BRA) and Venezuela ${ }^{20}$ (VEN). The Brazilian CPG was found in medical literature databases, and the others were found by Google searches. The guidelines were published in 2010 (COL), 2011 (BRA) (CHI) 2012 (ARG) and 2014 (VEN). The general characteristics of the assessed guidelines are shown in Table $\mathbf{1 .}$

\section{AGREE-II appraisal results}

The quality of CPGs was variable. In general, the guidelines received the lowest scores for rigour of development, applicability and editorial independence. With the exception of the BRA CPG, which obtained the highest score for editorial independence. In contrast, aspects relating to the scope and purpose, stakeholder involvement, and clarity of presentation of the guidelines received high scores (Table 2).

The median score of all guidelines was above $90 \%$ for the scope and purpose domain [mean 94.6\%; 95\% confidence interval (CI): $91.4 \%-97.8 \%$ ] and below $30 \%$ for the rigour of development (mean 29.6\%; 95\% CI: 20.7\%-38.4\%), 


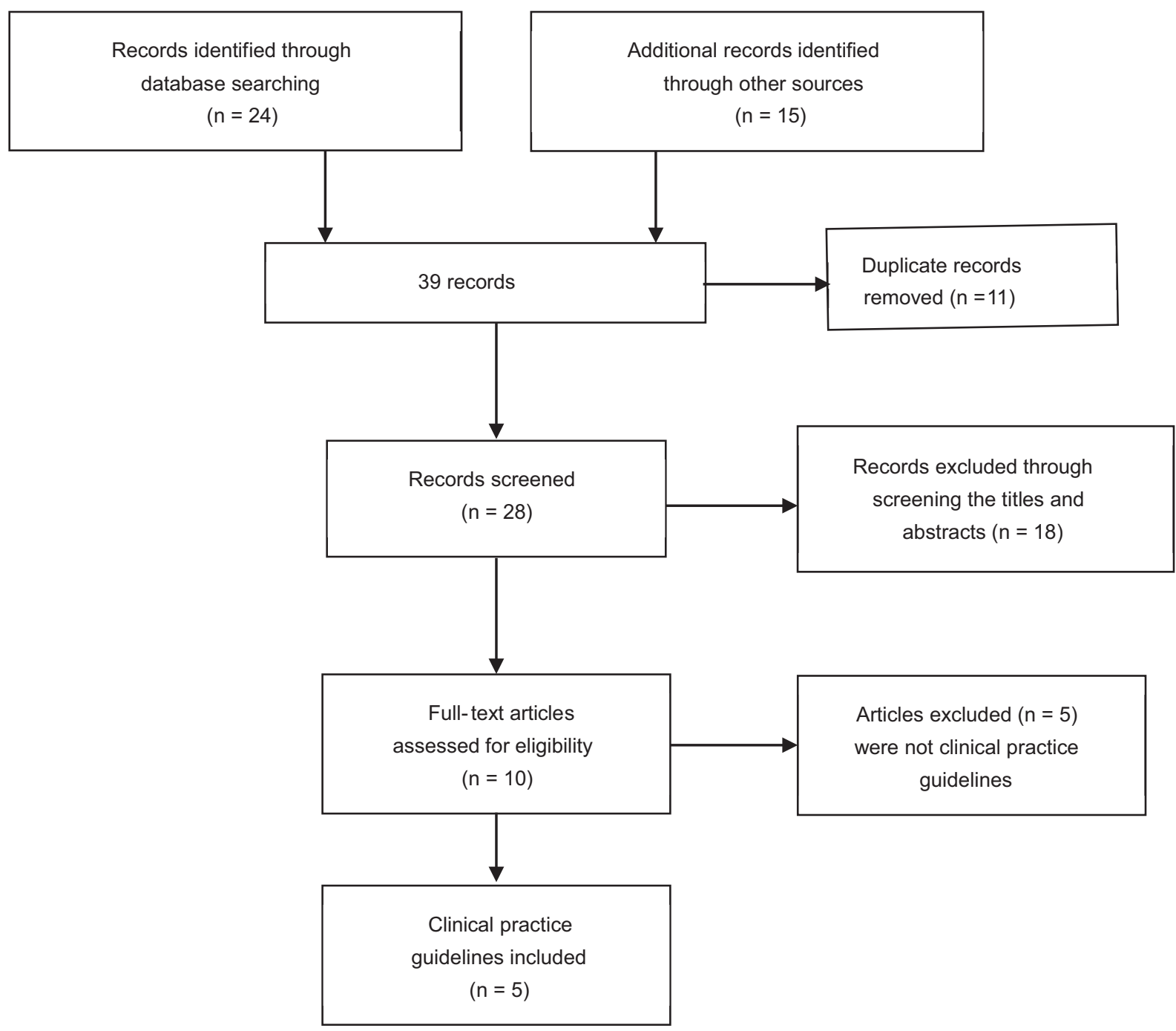

FIGURE 1 - Flow diagram of the search and selection process of clinical practice guidelines for Chagas disease.

TABLE 1: General characteristics of the included clinical practice guidelines.

\begin{tabular}{|c|c|c|c|c|c|}
\hline Guideline & $\begin{array}{c}\text { Year of } \\
\text { publication }\end{array}$ & Country & Organization & Development method & $\begin{array}{l}\text { Number of } \\
\text { references }\end{array}$ \\
\hline $\begin{array}{l}\text { Diagnosis, care and clinical } \\
\text { management of Chagas disease. }\end{array}$ & 2014 & Venezuela & $\begin{array}{l}\text { Ministry of Popular Power for } \\
\text { Health }\end{array}$ & Consensus & 122 \\
\hline $\begin{array}{l}\text { Diagnosis and treatment of patients } \\
\text { with Chagas disease. }\end{array}$ & 2012 & Argentina & $\begin{array}{l}\text { Ministry of Health in the } \\
\text { Presidency of the Nation }\end{array}$ & $\begin{array}{l}\text { Literature review and } \\
\text { consensus }\end{array}$ & 119 \\
\hline $\begin{array}{l}\text { Diagnosis, treatment and prevention of } \\
\text { Chagas disease. }\end{array}$ & 2011 & Chile & $\begin{array}{l}\text { Ministry of Health of the } \\
\text { Government }\end{array}$ & Not mentioned & 64 \\
\hline $\begin{array}{l}\text { I Latin American guidelines for the } \\
\text { diagnosis and treatment of Chagas } \\
\text { heart disease. }\end{array}$ & 2011 & Brazil & Brazilian Society of Cardiology & Consensus & 418 \\
\hline
\end{tabular}


TABLE 2: Domain scores for the five clinical practice guidelines using the AGREE-II instrument.

\begin{tabular}{|c|c|c|c|c|c|c|c|}
\hline Guideline & $\begin{array}{l}\text { Scope and } \\
\text { Purpose } \\
(\%)\end{array}$ & $\begin{array}{l}\text { Stakeholder } \\
\text { Involvement } \\
(\%)\end{array}$ & $\begin{array}{l}\text { Rigour of } \\
\text { Development } \\
\text { (\%) }\end{array}$ & $\begin{array}{l}\text { Clarity of } \\
\text { Presentation } \\
\text { (\%) }\end{array}$ & $\begin{array}{c}\text { Applicability } \\
(\%)\end{array}$ & $\begin{array}{c}\text { Editorial } \\
\text { Independence } \\
(\%)\end{array}$ & ICC \\
\hline $\begin{array}{l}\text { Diagnosis and treatment } \\
\text { of patients with Chagas } \\
\text { disease, } 2012\end{array}$ & 98 & 70 & 38 & 76 & 17 & 14 & 0.87 \\
\hline $\begin{array}{l}\text { Diagnosis, treatment and } \\
\text { prevention of Chagas } \\
\text { disease, } 2011\end{array}$ & 94 & 63 & 24 & 72 & 8 & 11 & 0.92 \\
\hline $\begin{array}{l}\text { Latin American guidelines for } \\
\text { the diagnosis and treatment } \\
\text { of Chagas heart disease, } \\
2011\end{array}$ & 96 & 61 & 36 & 80 & 13 & 64 & 0.90 \\
\hline $\begin{array}{l}\text { Median (95\% confidence } \\
\text { interval) }\end{array}$ & $94.6(91.4-97.8)$ & $63.2(58.1-68.3)$ & $29.6(20.7-38.4)$ & $70.4(60.2-80.6)$ & $11.4(6.7-16.1)$ & $22.8(5.8-51.4)$ & \\
\hline
\end{tabular}

AGREE: Appraisal of Guidelines Research and Evaluation; ICC: intraclass correlation coefficient.

applicability (mean 11.4\%; 95\% CI: 6.7\%-16.1\%) and editorial independence (mean 22.8\%; 95\% CI: 5.8\%-51.4\%) domains, (Figure 2).

The result of the inter-rater reliability assessment among the three reviewers was high: ICC was consistently $(>75 \%)$ excellent, with no ICC values found to be less than $40 \%$. The reliability of the reviewers was satisfactory. The ICCs for the guidelines in the COL, CHI, BRA, ARG, and VEN studies were $(0.93 ; 95 \%$ CI: $0.87-0.97),(0.92 ; 95 \%$ CI: $0.85-0.96)$, (0.90; 95\% CI: 0.80-0.95), (0.87; 95\% CI: 0.74-0.94) and (0.85; 95\% CI: 0.69-0.93), respectively.

Importantly, none of the selected CPGs linked their grade of recommendations to the level of evidence. Also, they did not mention how their recommendations were chosen, and we found no evidence of external review prior to the publication for any of the evaluated CPGs. Agreement between these CPGs on the grade of recommendations was not observed. The overall assessment of the quality of CPGs was moderate-to-low.

\section{Clinical practice guideline recommendations}

These indications were taken to monitor follow-up treatment in immunocompetent patients with Chagas disease in chronic phase, (Table 3).

Indication of treatment: only a guideline (BRA) recommended that treatment (BZN or NFX) should be used in adults with Chagas disease in chronic phase, based on evidence to that effect. The other CPGs (ARG, COL, CHI and VEN) did not raise evidence-based recommendations. However, these guidelines suggested that the treatment should be administered by analyzing each individual patient (risk-benefit analysis).
None of the guidelines mentioned the criteria for choosing one drug over the other (BZN or NFX).

Indication of treatment monitoring: all CPGs (ARG, BRA $\mathrm{COL}, \mathrm{CHI}$ and VEN) recommended that clinical follow-up should be performed during treatment and four guidelines (ARG, COL, CHI, VEN) recommended that clinical followup should be performed also with laboratory tests (complete blood count, liver and renal function tests and urinalysis). These recommended tests changed according to the guideline.

Treatment and dosage: all CPGs recommended that BZN and NFX were the only drugs available to treat Chagas disease. Both drugs are available as tablets for adults in the following strength: $100 \mathrm{mg}$ and $120 \mathrm{mg}$ for BZN and NFX, respectively.

The (BRA) and (VEN) guidelines recommended that BZN should be used at doses of $5 \mathrm{mg} / \mathrm{kg} /$ day for 60 days. However, the (BRA) recommended that BZN should be administered as the total daily dose in two or three divided doses and the CPG (VEN) proposed that BZN should be administered as the total daily dose in two divided doses. Moreover, the CPGs (CHI, ARG) recommended that BZN should be given at doses between $5-7 \mathrm{mg} / \mathrm{kg} /$ day. These guidelines differ in terms of how often the treatment is given. The CPG (CHI) recommended that BZN should be administered in three divided doses for 60 days. Conversely, the guideline (ARG) recommended that BZN should be administered in two divided daily doses for 60 days. Finally, the CPG (COL) recommended that BZN should be given a higher doses between $5-10 \mathrm{mg} / \mathrm{kg} /$ day in two or three divided daily doses for 60 days. BRA, COL and VEN guidelines recommended a maximum daily dose of 300mg. An upper dose limit (400mg) for BZN is also mentioned in the CPG (ARG). 


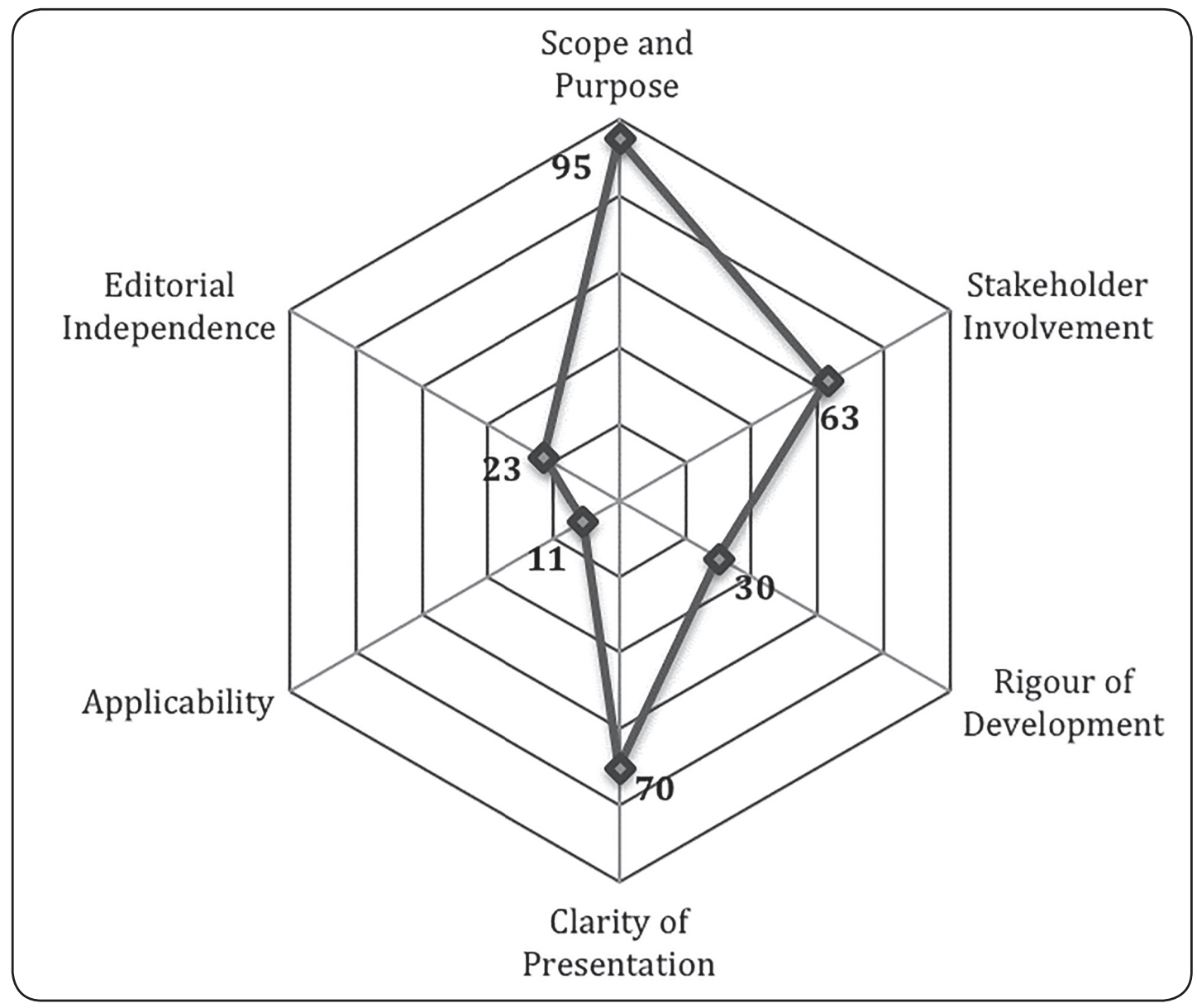

FIGURE 2 - Median scores of evaluated guidelines in six domains of AGREE II instrument.

TABLE 3: Summary of recommendations from clinical practice guidelines about treatment and monitoring of patients with Chagas disease.

\begin{tabular}{|c|c|c|c|c|}
\hline \multirow{2}{*}{ Guideline } & \multicolumn{2}{|c|}{ Recommendations for therapeutic drug } & \multicolumn{2}{|c|}{ Recommendations for therapeutic drug monitoring } \\
\hline & BZN & NFX & Laboratory test & Frecuency \\
\hline $\begin{array}{l}\text { Diagnosis, care and clinical } \\
\text { management of Chagas disease, } \\
2014\end{array}$ & $\begin{array}{l}5 \mathrm{mg} / \mathrm{kg} / \text { day } \mathrm{PO} \text { in } 2 \text { doses } \\
\text { x } 60 \text { days ( } \max 300 \mathrm{mg} / \\
\text { day) }\end{array}$ & $\begin{array}{l}5-8 \mathrm{mg} / \mathrm{kg} / \mathrm{day} \text { PO in } 2-3 \\
\text { doses } \times 60 \text { days }\end{array}$ & $\begin{array}{l}\text { Complete blood count, } \\
\text { liver and renal function } \\
\text { test. }\end{array}$ & $\begin{array}{l}\text { Before treatment starts, at } 20 \\
\text { days after starting and after } \\
\text { treatment ended }\end{array}$ \\
\hline $\begin{array}{l}\text { Diagnosis and treatment of } \\
\text { patients with Chagas disease, } \\
2012\end{array}$ & $\begin{array}{l}5-7 \mathrm{mg} / \mathrm{kg} / \text { day } \mathrm{PO} \text { in } 2 \\
\text { doses } x 60 \text { days (max } \\
400 \mathrm{mg} / \text { day) }\end{array}$ & $\begin{array}{l}8-10 \mathrm{mg} / \mathrm{kg} / \mathrm{day} \text { PO in } 3 \\
\text { doses } x 60 \text { days }(\max \\
700 \mathrm{mg} / \text { day })\end{array}$ & $\begin{array}{l}\text { Complete blood count, } \\
\text { liver and renal function } \\
\text { test. }\end{array}$ & $\begin{array}{l}\text { Before treatment starts and } \\
\text { at } 15-20 \text { days after starting }\end{array}$ \\
\hline $\begin{array}{l}\text { Diagnosis, Treatment and } \\
\text { Prevention of Chagas Disease, } \\
2011\end{array}$ & $\begin{array}{l}5-7 \mathrm{mg} / \mathrm{kg} / \text { day } \mathrm{PO} \text { in } 3 \\
\text { doses } \times 60 \text { days }\end{array}$ & $\begin{array}{l}8-10 \mathrm{mg} / \mathrm{kg} / \text { day } \mathrm{PO} \text { in } 3 \\
\text { doses } x 60 \text { or } 90 \text { days. (max } \\
700 \mathrm{mg} / \text { day) }\end{array}$ & $\begin{array}{l}\text { Complete blood count, } \\
\text { liver and renal function } \\
\text { test. }\end{array}$ & $\begin{array}{l}\text { Before treatment starts, at } 30 \\
\text { days after starting and after } \\
\text { treatment ended }\end{array}$ \\
\hline $\begin{array}{l}\text { I Latin American guidelines for } \\
\text { the diagnosis and treatment of } \\
\text { Chagas heart disease, } 2011\end{array}$ & $\begin{array}{l}5 \mathrm{mg} / \mathrm{kg} / \text { day } \mathrm{PO} \text { in } 2-3 \\
\text { doses } \times 60 \text { days (max } \\
300 \mathrm{mg} / \text { day) }\end{array}$ & $\begin{array}{l}8-10 \mathrm{mg} / \mathrm{kg} / \text { day } P O \text { in } 3 \\
\text { doses } \times 60 \text { days }\end{array}$ & Not reported & Not reported \\
\hline
\end{tabular}

BNZ: benznidazole; NFX: nifurtimox; PO: per os. 
Regarding the recommended regimen of NFX, all guidelines (except COL, VEN) adopted the regimen of $8-10 \mathrm{mg} / \mathrm{kg} /$ day in three divided doses. However, the duration of treatment was variable. The CPGs (BRA and ARG) recommended that NFX should be administered for 60 days. The guideline (CHI) recommended a longer period, between 60-90 days. The CPGs (CHI and ARG) recommended a maximum daily dose of $700 \mathrm{mg}$. Moreover, the guidelines (COL, VEN) recommended that NFX should be administered aa a lower daily dose, between 5-8mg/ $\mathrm{kg} /$ day in two or three divided doses for 60 days.

None of CPGs (ARG, COL, CHI, BRA, VEN) supported its evidence-based recommendations for dosage, number of daily doses and duration of treatment.

Treatment monitoring with laboratory tests: four CPGs (ARG, COL, CHI, VEN) recommended that laboratory tests (complete blood count, creatinine, blood urea nitrogen, alanine aminotransferase, aspartate aminotransferase and urinalysis) should be used to monitor treatment. The complete blood count, creatinine, blood urea nitrogen, alanine aminotransferase and aspartate aminotransferase were common tests in the four guidelines. The Colombian guideline is the only one that recommends uroanalysis for the monitoring of the treatment. None of the CPGs supported its evidence-based recommendations for the use of laboratory tests in treatment monitoring.

Frequency of treatment monitoring: The frequencies for monitoring treatment (BZN or NFX) were different in each guideline. The CPG (ARG), recommended that at least two clinical follow-ups with laboratory tests (blood count, renal function, liver function and pregnancy test in the case of women) during treatment should be done before starting treatment, and 15-20 days after the start. Unlike previous recommendations, the guidelines (CHI, VEN) proposed that there should be made at least three clinical follow-up visits, with laboratory tests (blood count, renal function and liver function) during treatment as well: before starting treatment, half and the end of treatment. By contrast, the CPG (COL) recommended that should make a greater number of clinical follow-ups (four) with laboratory tests (blood count, renal function, liver function and urinalysis) before starting treatment, at 20 and 40 days after the start and the end of treatment. Moreover, the CPG (BRA) did not indicate how often these follow-ups should be performed in patients. None of CPGs (ARG, BRA, COL, CHI, VEN) supported its evidence-based recommendations for treatment monitoring.

\section{DISCUSSION}

The assessment of the quality and consistency of the guidelines on the therapeutic drug monitoring of Chagas disease in adults in the chronic phase of infection showed that there was no association between the methods used to develop the CPGs, and the recommendations that were made. This assessment evidenced the lack of standardized processes in the development of these CPGs, which resulted in documents of varying quality, which also showed that none of the CPGs supported its evidence-based recommendations. Guideline developers should adhere to a standardized evidence-based evaluation system.
Although all CPGs clearly presented their recommendations on management and monitoring of drugs, none of them assessed the strength and consistency of the evidence that supported the recommendations. Therefore, the specific recommendations of the guidelines for therapeutic drug monitoring of BZN and NFX were not graded and varied with respect to the total daily dose, number of doses per day, total time of treatment, number of clinical controls and laboratory tests. There is evidence that the implementation of evidence-based guidelines can improve the quality of care ${ }^{21}$.

The quality of the GPCs in the different domains was heterogeneous, based on the criteria of the AGREE II instrument. The domains that received the poorest scores were rigor of development, applicability, and editorial independence. This could be due to lack of systematic search strategies, lack of tools to facilitate implementation of recommendations and no specification of potential competing interests, respectively ${ }^{22}$. However, low scores can also be explained by poor reporting. The remaining three domains of scope and purpose, stakeholder involvement and clarity of presentation of the guidelines received high scores. These results are similar to a recent review of 11 reviews of CPGs of hypertension, which showed that the domains, rigour of development, applicability, and editorial independence scored consistently low across the $\mathrm{CPGs}^{23}$.

Importantly, the overall assessment of the quality of CPGs was moderate to low. It indicates that more efforts are needed to improve these CPGs, especially with respect to the domain of rigor of development, which is considered to be crucial for the guideline quality and to determine whether the recommendations are really based on evidence. In order to establish evidencebased recommendations and clinically valid in all CPGs, developers should implement systematic methods for rating quality of evidence and strength of recommendations ${ }^{24}$. This finding is similar to a study of 42 reviews of CPGs of healthcare topics published, which showed that despite some increase in quality of CPGs over time, the quality scores as measured with the AGREE Instrument have remained moderate to low over the last two decades ${ }^{25}$.

In this review, the recommendations that addressed the same topic varied from guideline-to-guideline according to the different domains.

This could be explained by the low quality evidence because when evidence is uncertain, judgments about magnitude of intervention effects are often swayed by subjective impressions ${ }^{26}$. With such deficiencies in the methodological quality of CPGs, there is no guarantee that the recommendations would result in better health-related outcomes for patients with Chagas disease ${ }^{25,27}$.

Paradoxically, the safety of drugs for Chagas disease is not fully known, although these were introduced over 40 years ago ${ }^{28}$. While the safety of drugs is critical for health care, performing laboratory testing without being sure of its significance or relevance, rather than helping the patient can become an unnecessary burden on the health system ${ }^{29}$.

The main limitations of this review are as follows. First, assessment of methodological quality was based on what was 
reported by CPG developers, who may not have truly reflect the process of developing them, and that there was inadequate information provided. Second, only the AGREE-II instrument was used in evaluating the quality of the CPGs, nowadays the most comprehensive validated assessment tool. Although others instruments could be additionally employed ${ }^{30}$.

In conclusion, the review showed that the methodological quality of CPGs for Chagas disease was not generally desirable, and there was no explicit link between the best available evidence and the recommendations. In addition, significant differences were found in terms of the recommendations on the pharmacological management, mainly, duration of treatment, number of clinical controls and laboratory tests. These differences can create barriers to accessing care, treatment, and ultimately lead the patients to experience worse health outcomes. It is necessary that the guidelines for the management of Chagas disease be updated, desirably, according to methodological tools.

\section{Conflict of interest}

The authors declare that there is no conflict of interest.

\section{REFERENCES}

1. Bern C. Chagas' disease. N Engl J Med. 2015;373(5):456-66.

2. World Health Organization. Chagas disease in Latin America: an epidemiological update based on 2010 estimates. Wkly Epidemiol Rec. 2015;33-44.

3. Croft SL, Barrett MP, Urbina JA. Chemotherapy of trypanosomiases and leishmaniasis. Trends Parasitol. 2005;21(11):508-12.

4. Rassi Jr A, Rassi A, Marcondes de Rezende J. American trypanosomiasis (Chagas disease). Infect Dis Clin North Am. 2012;26(2):275-91.

5. Villar JC, Perez JG, Cortes OL, Riarte A, Pepper M, Marin-Neto JA, et al. Trypanocidal drugs for chronic asymptomatic Trypanosoma cruzi infection. Cochrane Database Syst Rev. 2014;27(5):CD003463.

6. Rassi Jr A, Rassi A, Marin-Neto JA. Chagas disease. Lancet. 2010;375(9723):1388-402.

7. Morillo CA, Marin-Neto JA, Avezum A, Sosa-Estani S, Rassi Jr A, Rosas F, et al. Randomized trial of benznidazole for chronic Chagas' cardiomyopathy. N Engl J Med. 2015;373(14):1295-306.

8. Fragata-Filho AA, Franca FF, Fragata CS, Lourenço AM, Faccini $\mathrm{CC}$, Costa CA. Evaluation of parasiticide treatment with benznidazol in the electrocardiographic, clinical, and serological evolution of Chagas disease. PLoS Negl Trop Dis. 2016;10(3):e0004508.

9. Jackson Y, Alirol E, Getaz L, Wolff H, Combescure C, Chappuis F. Tolerance and safety of nifurtimox in patients with chronic Chagas disease. Clin Infect Dis. 2010;51(10):e69-75.

10. Miller DA, Hernandez S, Rodriguez De Armas L, Eells SJ, Traina MM, Miller LG, et al. Tolerance of benznidazole in a United States Chagas Disease clinic. Clin Infect Dis. 2015;60(8):1237-40.

11. Antinori S, Grande R, Bianco R, Traversi L, Cogliati C, Torzillo D, et al. High frequency of adverse reactions and discontinuation with benznidazole treatment for chronic Chagas disease in Milan, Italy. Clin Infect Dis. 2015;60(12):1873-75.

12. Olivera MJ, Cucunubá ZM, Álvarez CA, Nicholls RS. Safety profile of nifurtimox and treatment interruption for chronic Chagas disease in Colombian adults. Am J Trop Med Hyg. 2015;93(6):1224-30.
13. Marin-Neto JA, Rassi Jr A, Morillo CA, Avezum A, Connolly SJ, Sosa-Estani S, et al. Rationale and design of a randomized placebocontrolled trial assessing the effects of etiologic treatment in Chagas' cardiomyopathy: the BENznidazole Evaluation For Interrupting Trypanosomiasis (BENEFIT). Am Heart J. 2008;156(1):37-43.

14. Sperandio da Silva GM, Mediano MF, Alvarenga Americano do Brasil PE, da Costa Chambela M, da Silva JA, de Sousa AS, et al. A clinical adverse drug reaction prediction model for patients with chagas disease treated with benznidazole. Antimicrob Agents Chemother. 2014;58(11): 6371-7.

15. Brouwers MC, Kho ME, Browman GP, Burgers JS, Cluzeau F, Feder $\mathrm{G}$, et al. AGREE II: advancing guideline development, reporting and evaluation in health care. J Clin Epidemiol. 2010;63:1308-11.

16. Ministerio de la Protección Social. Guía para la atención clínica integral del paciente con enfermedad de Chagas. Bogotá, República de Colombia. Bogotá: 2010. 84p. https://www.google. com.co/?gws_rd=cr\&ei=_ABjU86RNsOlyAThkoDwBw\#q=Mi nisterio + de+la+Protección + Social.+Guía+para+la+atención+clín ica + integral + del + paciente + con + enfermedad + de + Chagas. + Bogo tá,+República+de+Colombia+2010.

17. Ministerio de Salud de la Nación. Guías para la atención al paciente infectado con Trypanosoma cruzi (Enfermedad de Chagas). Buenos Aires: 2012. 79p. http://www.msal.gob.ar/chagas/images/stories/ Equipos/Guia_Nacional_Chagas_version_27092012.pdf

18. Ministerio de Salud. Guía Clínica "Guía de Diagnóstico, Tratamiento y Prevención de la Enfermedad de Chagas." Santiago: 2011. 38p. http://ivl.ispch.cl/_Documentos\%5CTrypanosoma\%5CG u\%C3\%ADa_Clinica_Enf_de_Chagas_2011.pdf

19. Andrade JP, Marin-Neto JA, Paola AAV, Vilas-Boas F, Oliveira GM, Bacal F, et al. I Latin American Guidelines for the diagnosis and treatment of Chagas' heart disease: executive summary. Arq Bras Cardiol. 2011;96(6):434-42.

20. Ministerio del Poder Popular para la Salud. Guía para el Diagnostico, Atención y Manejo Clínico de la Enfermedad de Chagas en Venezuela. Maracay: 2014; 71p. http://svmi.web.ve/wh/documentos/ Guia_Chagas_2015.pdf

21. Lugtenberg M, Burgers JS, Westert GP. Effects of evidence-based clinical practice guidelines on quality of care: a systematic review. Qual Saf Health Care. 2009;18(5):385-92.

22. Chang SG, Kim DI, Shin ES, Jang JE, Yeon JY, Lee YS. Methodological Quality appraisal of 27 Korean guidelines using a scoring guide based on the AGREE II Instrument and a web-based evaluation. J Korean Med Sci. 2016;31(5):682-7.

23. Al-Ansary LA, Tricco AC, Adi Y, Bawazeer G, Perrier L, AlGhonaim M, et al. A systematic review of recent clinical practice guidelines on the diagnosis, assessment and management of hypertension. PLoS One. 2013;8(1):e53744.

24. Olivera MJ, Fory JA, Olivera AJ. Quality assessment of clinical practice guidelinesfor Chagas disease. Rev Soc Bras Med Trop. 2015;48(3):343-6.

25. Alonso-Coello P, Irfan A, Solà I, Gich I, Delgado-Noguera M, Rigau $\mathrm{D}$, et al. The quality of clinical practice guidelines over the last two decades: a systematic review of guideline appraisal studies. Qual Saf Health Care. 2010;19(6):e58.

26. Woolf S, Schünemann HJ, Eccles MP, Grimshaw JM, Shekelle P. Developing clinical practice guidelines: types of evidence and outcomes; values and economics, synthesis, grading, and presentation and deriving recommendations. Implement Sci. 2012;7:61. doi: 10.1186/1748-5908-7-61.

27. Penaloza B. Critically appraised article: The quality of clinical practice guidelines over the last two decades: a systematic review of guidelines appraisal studies. Rev Med Chil. 2014;142(1):105-8. 
28. Fernández ML, Marson ME, Ramirez JC, Mastrantonio G, Schijman AG, Altcheh J, et al. Pharmacokinetic and pharmacodynamic responses in adult patients with Chagas disease treated with a new formulation of benznidazole. Mem Inst Oswaldo Cruz. 2016;111(3):218-21.

29. Francke AL, Smit MC, de Veer AJE, Mistiaen P. Factors influencing the implementation of clinical guidelines for health care professionals: a systematic meta-review. BMC Med Inform Decis Mak. 2008;8:38. doi: 10.1186/1472-6947-8-38.

30. Brouwers MC, Kho ME, Browman GP, Burgers JS, Cluzeau F, Feder G, et al. The Global Rating Scale complements the AGREE II in advancing the quality of practice guidelines. J Clin Epidemiol. 2012;65(5):526-34. 